(iipDIP: $18.01 .018 / 20200803$, DOI: $10.25215 / 0803.018$

http://www.ijip.in

Research Paper

\title{
Exam anxiety in college students
}

\author{
Nisha Pagaria ${ }^{1 *}$
}

\section{ABSTRACT}

Test anxiety is a psychological condition in which individuals experience outrageous distress and anxiety in testing circumstances. It is a form of performance anxiety. Fear of exams influence the academic performance of students in the exam. It is an irrational distress that can also lead to avoidance of the feared situation. The objective was to study the level of test anxiety in college students and observe the gender difference in test anxiety. Using purposive sampling, the sample size consisted of 120 undergraduate students (Male $=60$, Female $=60$ ). The instrument used for the study was Westside Test Anxiety Scale. The mean score and standard deviation of test anxiety are 28.18 and 7.65 respectively. The t-test was conducted to observe the gender difference in test anxiety. The results came out to be that there is a significance difference between male and female college students on test anxiety.

Keywords: Test anxiety, gender difference in test anxiety, college students

0 tress is a survival mechanism. So, when we experience stress for a long time and our body doesn't adapt to it, it causes anxiety. Thus, it is a feeling that is portrayed by thoughts of strain, stressed thoughts, and physical changes. Anxiety also leads to flight or fight response. Every 1 in 4 Indian suffers from anxiety. Symptoms of anxiety are -

Physical symptoms like sweating, trembling, agitation, nausea, dizziness, tense muscles, racing heart, dry mouth, shaky hands. Emotional symptoms like anger, guilt, helpless, shame, fear, disappointment.

Test anxiety is a very common issue experienced by many students. Hence, it is a psychological condition in which people experience outrageous distress and anxiety in testing circumstances. It has been studied officially since the early 1950s commencing with researchers George Mandler and Seymour Sarason. Numerous individuals experience pressure or nervousness before a test. Indeed, a little apprehension can really assist you with playing out your best. However, when this distress turns out to be unnecessary to such an extent that it really interferes with performance on a test, it is known as test anxiety. Test nervousness can likewise turn into an endless loop. In the wake of encountering tension during one test, students may turn out to be so frightful about it happening again and again that they really become anxious during the following or next test. After over and over suffering test anxiety, students may start to feel that they have no capacity to change the

${ }^{1}$ Research Scholar, Amity University, Delhi, India

*Responding Author

Received: July 04, 2020; Revision Received: August 05, 2020; Accepted: September 25, 2020

(C) 2020, N Pagaria; licensee IJIP. This is an Open Access Research distributed under the terms of the Creative Commons Attribution License (www.creativecommons.org/licenses/by/2.0), which permits unrestricted use, distribution, and reproduction in any Medium, provided the original work is properly cited. 
circumstance. Fear of exams influence the academic performance of students in the exam. It is an irrational distress that can also lead to avoidance of the feared situation. According to Onukwufor \& Ugwu (2017), the fear and worry which the examinee shows during test or examination is acknowledged as test anxiety. Psychologists Liebert and Morris (1967) examined the structure of test anxiety on two discrete factors: Cognitive Test Anxiety and Emotionality. Emotionality implies that the individual shows elevated levels of different side effects recognized with test anxiety that can be seen through physiological reactions experienced during circumstances where they are being assessed, for example, a test. The other factor referenced is Cognitive Test Anxiety, otherwise called stress/worry. It is related to the people's psychological responses to circumstances where they are being assessed, in the occasions former, during, and after those tasks. According to Shashank (2008), more than $50 \%$ of students suffer from an exam phobia. Generally, students who have exam phobia they tend to feel that they will embarrass themselves or they will be negatively judged due to their performance. It creates the hindrance among students and it also increases/decreases the amount of sleep. Exams can provoke anxiety in students and thus students start feeling tensed, nausea, uneasiness, heaving racing thoughts, sweaty palms, etc. Due to this irrational fear, sometimes student's mind goes blank during the exam, due to which he/she starts panicking.

Exam performance are interfered with feelings too. Ormrod (2008), defined test anxiety as "excessive anxiety about a particular test or about assessment in general". Thus, students start considering exams as burden and tend to avoid it as much as possible. It is a form of performance anxiety.

Causes of test anxiety can be low motivation level, high expectations from loved ones, lack of preparation, rising competition, not able to manage your emotions, afraid of poor performance, low self-esteem.

\section{TREATMENT OF TEST ANXIETY}

1. Psychotherapy- Cognitive behavioral therapy (CBT), the objective of Cognitive behavioral therapy for anxiety is to distinguish and address negative considerations and convictions. So, it helps individual who are dealing with exam anxiety by changing the way they think and change the way they feel.

2. Exposure therapy- The objective of Exposure therapy for anxiety is to help to challenge their fears. It takes advantage of the belief of extinction (i.e. when you're no longer scared of a feared stimulus) by introducing you to the feared stimulus gradually until you're not frightened anymore.

3. Medications by Psychiatrist- Beta-blockers and Sedatives.

\section{How to cope with exam anxiety}

1. Preparation- Break your study material in parts, so that you can understand well because when you try to do everything together you start being anxious or panicking.

2. Manage your emotions- There are things that we can't control like the questions that would be there in exam, so you need to learn about how to manage your emotions so that your anxiety doesn't get out of control and affects your academic performance.

3. Challenge your self- If you are not able to perform well, then don't feel sad rather fight the situation because once you fight with your fear you will start considering your fear as your strength.

4. Relaxation technique- To help you with staying calm and confident before and during the test, perform relaxation techniques, for example, deep breathing, loosening or 


\section{Exam anxiety in college students}

relaxing up your muscles each in turn, or closing your eyes and visualizing a positive result.

5. Sleep- Take enough sleep, otherwise you will stress yourself. So, try to clear your mind the day before your exam is, by imagining about the positive things and believing in yourself.

\section{Objective}

1. To study the level of test anxiety in college students.

2. Gender Differences in Westside Test Anxiety Scale.

\section{Hypothesis}

- There will be a significant difference between male and female college students on Test Anxiety.

\section{METHODOLOGY}

\section{Sample}

The sampling technique for this research used was purposive sampling. The sample for the study consisted of undergraduate college students. The sample size was 120 college students (Males $=60$ and Females $=60$ ) aged between 18-21 years.

\section{Tool}

The instrument used for the study was Westside Test Anxiety Scale.

Westside Test Anxiety Scale- The Westside Test Anxiety Scale was proposed by Richard Driscoll and is a brief, ten item standard scale intended to find students with anxiety impairments who could get advantage from an anxiety-reduction intervention. The tool covers self-assessed anxiety impairment and cognitions which can impair performance. Correlations between anxiety-reduction as measured by the tool and enhancements in test performance were used as the validation criteria. The average correlation was $r=.44$, representing that changes in the Westside scale accounted for $20 \%$ of changes in these objective tests. The Westside Test Anxiety Scale includes six items measuring impairment, four items on worry and dread, and no items on physiological over-arousal. Each item was measured on an ordinal 5-point Likert-type scaling (The 5 options and scores were as follows- 'Never' $=1$; 'Rarely' $=2$; 'Sometimes' $=3$; 'Often' $=4$; 'Always' $=5$ ).

In this research, the Independent Variable is gender and Dependent Variable is test anxiety.

\section{RESULT}

There were total 120 participants $($ Male $=60$ and Female $=60)$. Means and standard deviation were found out as follows:

Table1: Comparison of gender difference on Test Anxiety

\begin{tabular}{ccccccc} 
Test Anxiety & \multicolumn{2}{c}{ Males } & \multicolumn{2}{c}{ Females } & $\boldsymbol{t}(112)$ & $\boldsymbol{p}$ \\
& $\boldsymbol{M}$ & SD & $\boldsymbol{M}$ & $\boldsymbol{S D}$ & & \\
\hline & 26.68 & 8.35 & 29.68 & 6.61 & 1.98 & 0.03
\end{tabular}

t-Test was conducted to check whether there was a significance difference between Male and Female college students in Test Anxiety. It was found that there was a significant difference for gender, $\mathrm{t}(112)=1.98, \mathrm{p}=0.03$, female $(\mathrm{M}=29.68, \mathrm{SD}=6.61)$ and male $(\mathrm{M}=26.68, \mathrm{SD}=8.35)$. Therefore, the alternative hypothesis is accepted as there is a significance difference found between male and female college students in test anxiety. 


\section{DISCUSSION}

The aim was to study the level of test anxiety in college students and finding out the gender difference in test anxiety with the help of Westside Test Anxiety Scale by Richard Driscoll. The result in table 1 showed that there is a significance difference between male and female college students in test anxiety. Females have high anxiety as compared to males. These results can be supported by previous researches done on gender difference in test anxiety like Lowe P.A., (2018) conducted a study on an investigation into the psychometric properties of the TAM-C ( the results showed that the gender difference were found on four of the TAM-C scales, with females detailing more elevated levels of test anxiety than males); Peña N., Isabel M., Pellicioni S., et al (2016) conducted a study on gender difference in test anxiety and their impact on higher education students' academic achievement (the results came out to be that female students showed higher levels of test, math, and trait anxiety as compared to male); Shekhar C., Devi R.,(2012) conducted study on achievement motivation across gender and different academic majors( the results came out to be that there was difference in achievement motivation of sciences and arts stream among male and female college students), Other researchers suggest that there is no significance difference in male and female college students in terms of academic achievement like [Adsul et al. (2008)], [Nagarathanamma \& Rao (2007)], [Kaushik \& Rani (2005)]. Hence, the findings of this study add more information about test anxiety and gender differences observed in terms of test anxiety.

The reason for the gender difference is text anxiety could be the social roles that are assigned to them due to which females are under greater pressure to perform well in academics than males; the other reason could be that males are more guarded than females with regards to declaring anxiety, as doing so might be experienced as undermining their masculinity.

\section{Limitations}

The limitation of the present study is that the smaller number of samples, so it is recommended to carry out research in relation to gender difference in test anxiety on a large sample size.

It is recommended that further studies should be done on a larger sample to find out that there is/isn't significance difference in gender in terms of test anxiety.

\section{REFERENCES}

Adsul, R. K., Kamble, V., \& Sangli, K. W. (2008). Achievement motivation as a function of gender, economic background and caste differences in college students. Journal of the Indian Academy of Applied Psychology, 34(2), 323-327.

Cassidy, J\& Johnson. R. (2001). Cognitive Test Anxiety and Academic Performance. Contemporary Educational Psychology, 27,270-295.

Kaushik, N., \& Rani, S. (2005). A Comparative study of achievement motivation, home environment and parent child relationship of adolescents. Journal of Psychological research, 49, 189-194.

Liebert, R. M., \& Morris, L. W. (1967). Cognitive and emotional components of test anxiety: A distinction and some initial data. Psychological reports, 20(3), 975-978.

Lowe, P. A. (2018). An investigation into the psychometric properties of the Test Anxiety Measure for College Students. Journal of Psychoeducational Assessment, 36(4), 322336. 


\section{Exam anxiety in college students}

Mandler, G., \& Sarason, S. B. (1952). A study of anxiety and learning. The Journal of Abnormal and Social Psychology, 47(2), 166-173.

Núñez Peña, M. I., Suárez Pellicioni, M., \& Bono Cabré, R. (2016). Gender differences in test anxiety and their impact on higher education students' academic achievement. Procedia-Social and Behavioral Sciences, 2016, vol. 228, p. 154-160.

Nagarathanamma, B., \& Rao, V. T. (2007). Achievement motivation and academic achievement of adolescent boys and girls. Indian Psychological Review, 68(3), 131.

Onukwufor, J.N. \& Ugwu, C.J. (2017). Self- concept, test anxiety and achievement motivation as predictors of academic achievement in physics among secondary school students in Rivers State Nigeria. Journal of Education and Practice,8, (33),99-106.

Ormrod, J.E. (2008). Educational Psychology: Developing learners ( $6^{\text {th }}$ ed) New Jersey: Reason Prentice Hall.

Shekhar, C., \& Devi, R. (2012). Achievement motivation across gender and different academic majors. Journal of Educational and Developmental Psychology, 2(2), 105.

Suárez-Pellicioni, M., Núñez-Peña, M. I., \& Colomé, À. (2016). Math anxiety: A review of its cognitive consequences, psychophysiological correlates, and brain bases. Cognitive, Affective, \& Behavioral Neuroscience, 16(1), 3-22.

\section{Acknowledgements}

The author cherished all those who participated in the study and guided /helped to facilitate the research process.

\section{Conflict of Interest}

The author declared no conflict of interest.

How to cite this article: N Pagaria (2020). Exam anxiety in college students. International Journal of Indian Psychology, 8(3), 136-140. DIP:18.01.018/20200803, DOI:10.25215/0803.018 